\title{
SOINS AUX FAMILLES DES MILITAIRES
}

L'organisation sanitaire de l'armée commence à prendre en mains la surveillance médicale des familles de ses ressortissants. L'on vient de créer à Strasbourg la première policlinique médicomilitaire allemande pour femmes et enfants 1 . Ouverte le $1 \mathrm{er}$ janvier 1910, dirigée par des médecins militaires, pourvue d'une salle d'opérations, de quelques lits pour traitements après opérations, de salles de consultations pour femmes et pour enfants, la policlinique nouvelle avait donné, au 1er janvier 1911, plus de mille consultations pour femmes el plus de 800 pour enfants, avec 27 opérations en tout. Quelques femmes dépendant d'autres garnisons sont venues demander des soins dans la policlinique de la garnison de Stras. bourg.

Les services rendus par ce rouage nouveau quant aux soins a donner aux nourrissons ont été particulièrement appréciés. L'accroissement des consultations cette année-ci, seconde année d'activité de la policlinique, est considérable déjà, et a bénéficié du concours très efficace du Militär-Frauenverein de Strasbourg.

Dr F.

\section{REPUBLIQUE ARGENTINE}

\section{LA CROIX-ROUGE ARGENTINE EN 1910}

Les statuts de la Croix-Rouge de la République argentine prévoient un compte renđu annuel que le président doit présenter au cours d'une des assemblées générales. Conformément à cette prescription, M. Manuel-Fernandez Cutiellos, son président actuel, a présenté à la réunion du 5 juin dernier, un mémoire dont nous extrayons ce qui suit :

${ }^{1}$ Deutsche militärärztliche Zeitschrift, 1911, n 16, p. 650. 